\title{
Author Correction: Gene regulation by long non-coding RNAs and its biological functions
}

Luisa Statello (D), Chun-Jie Guo, Ling-Ling Chen (1D) and Maite Huarte (D)

Correction to: Nature Reviews Molecular Cell Biology https://doi.org/10.1038/s41580-020-00315-9, published online 22 December 2020.

Grants information was added to the Acknowledgements. The changes have been made in the HTML and PDF versions of the article.

https://doi.org/10.1038/s41580-021-00330-4 I Published online 8 January 2021

๑) Springer Nature Limited 2021

\section{Author Correction: Two precious lessons from the HIV-1 RT structure}

\section{Giancarlo Abis}

Correction to: Nature Reviews Molecular Cell Biology https://doi.org/10.1038/s41580-020-00311-z, published online 28 October 2020.

In the original text, defunct designations were used for the two subunits of the HIV reverse transcriptase; the correct designations are p66 and p51. The changes have been made in the HTML and PDF versions of the article.

https://doi.org/10.1038/s41580-021-00329-x I Published online 8 January 2021

๑) Springer Nature Limited 2021 